\title{
PERANCANGAN PREVENTIVE MAINTENANCE ALAT BERAT DI PT. KALIMANTAN PRIMA PERSADA
}

\author{
Irawan Noor \\ Program Studi Teknik Industri, Fakultas Teknik \\ Universitas Islam Kalimantan Muhammad Arsyad Al Banjari Banjarmasin \\ J1. Adhyaksa No 2 Kayu Tangi Banjarmasin 70123 Indonesia \\ e-mail : irawan.noor@gmail.com
}

\begin{abstract}
Abstrak- Penjadwalan adalah proses pengaturan penentuan waktu pelaksanaan proses perawatan. Tujuan dilaksanakannya proses penjadwalan ini adalah untuk melakukan pengaturan waktu yang optimum sehingga proses perawatan dapat di laksanakan sebaik-baiknya dengan penggunaan sumber daya yang seefisien mungkin. Aktivitas penjadwalan dilakukan sebelum kegiatan perawatan mulai dilaksanakan dan sangat berkaitan erat dengan strategi perawatan yang akan dilakukan untuk unit tersebut. Dari strategi yang telah ditentukan maka semua aktivitas yang akan dilakukan dalam proses perawatan tersebut ditentukan waktu pelaksanaannya. Pengaturan ini sangat penting karena berkaitan dengan pengaturan pemanfaatan sumber daya, baik itu sumber daya manusia ataupun peralatan kerja dan suku cadang. Penjadwalan yang baik akan menghasilkan efisiensi yang tinggi dalam hal pemanfaatan sumber daya dengan tanpa mengurangi kualitas dari proses hasil perawatannya itu sendiri. Tujuan penelitian ini adalah untuk membuat rancangan jadwal Preventive Maintenance (PM) alat berat di PT Kalimantan Prima Persada. Hasil penelitian ini menunjukan bahwa setelah dibuat penjadwalan: rusak mendadak menjadi minim, kesiapan alat beroperasi menjadi tinggi, dan kondisi unit menjadi terpelihara. Karena pekerjaan yang sebelumnya telah direncanakan (schedule) untuk dikerjakan, maka memiliki waktu pelaksanaan yang lebih cepat dibandingkan dengan pekerjaan sama yang tidak terencana (unschedule).
\end{abstract}

Kata Kunci : Perencanaan Jadwal, Preventive Maintenance (PM).

\section{PENDAHULUAN}

$\mathrm{D}$ alam dunia industri alat berat merupakan benda produksi. Perusahaan membeli alat berat tersebut untuk menghasilkan output yang memiliki nilai ekonomis. Seringkali alat berat yang dimiliki oleh perusahaan merupakan alat kerja utama yang digunakan dalam menjalankan bisnis khususnya dalam bidang pertambangan. Sehingga alat berat yang dioperasikan memiliki peranan penting dalam menentukan untung ruginya usaha yang dijalankan. Ada dua hal mendasar yang menentukan apakah keuntungan atau kerugian yang akan didapat oleh pemilik alat berat, yaitu hasil produksi dan biaya operasional.

Untuk bisa memperoleh keuntungan yang diharapkan tentu saja pemilik alat berat harus melakukan menajemen terhadap alat berat tersebut. Dalam hal ini memperoleh hasil produksi yang semaksimal mungkin sesuai dengan target yang sudah ditentukan dengan berdasarkan rencana produksi yang realistis sesuai dengan kapasitas produksi alat tersebut, medan kerja serta kondisi lingkungan sekitar yang di hadapi. Sedangkan yang dimaksud dengan penggunaan biaya seoptimal mungkin adalah suatu usaha memperoleh manfaat yang semaksimal mungkin dari semua biaya yang timbul dari pengoperasian alat yang digunakan. Kebanyakan pemilik alat berat terjebak untuk menekan biaya operasional alat berat. Namun, perlu dipertimbangkan juga akibat yang timbul akibat penekanan biaya tersebut apakah sebanding dengan keuntungan yang diperoleh. Secara eksplisit usaha untuk mengeluarkan biaya seoptimal mungkin adalah proses mengelola resiko (risk management). Preventive maintenance dapat terlaksana dengan baik apabila ada perencanaan jadwal. Penelitian ini membahas mengenai perencanaan jadwal preventive maintenance. Tujuan penelitian ini untuk membuat rancangan jadwal Preventive Maintenance (PM) alat berat di PT Kalimantan Prima Persada.

\section{Penjadwalan/Scheduling}

Elemen keenam dari manajemen perawatan adalah penjadwalan atau scheduling. Aktivitas penjadwalan dilakukan sebelum kegiatan perawatan mulai dilaksanakan dan sangat berkaitan erat dengan strategi perawatan yang akan dilakukan untuk unit tersebut. Untuk memudahkan proses penjadwalan maka dapat menggunakan perangkat lunak yang telah disediakan oleh Komatsu ataupun yang dibangun oleh PT. United Tractors sendiri yaitu Maintenance Control System dan Asset Management Tool. Perangkat lunak tersebut juga mampu melakukan proses pencatatan data sehingga membantu dalam proses analisa ataupun pembuatan laporan aktivitas perawatan.

\section{Kesiapan Alat/Physical Availability (PA)}

Physical Availability (PA) telah lama digunakan sebagai benchmark pada industri pertambangan. Physical Availability menunjukkan besar tingkat kesiapan alat untuk operasi dengan rumus:

$$
P A=\frac{\sum \text { Schedule Time }-\Sigma R \& M \text { Time }}{\Sigma \text { Schedule Time }} \times 100 \%
$$

PA memiliki keterbatasan karena ada beberapa macam formula dan metode perhitungan PA yang berbeda. Sebagai hasilnya maka PA ini lebih efektif bila digunakan 
sebagai benchmark internal saja dibandingkan sebagai alat pembanding PA antara perusahaan (karena ada kemungkinan formula yang digunakan berbeda). Keterbatasan kedua karena informasi yang diberikan oleh PA sendiri kurang memadai,satuan PA memberikan gambaran hubungan antara dua faktor, tetapi satuan PA sendiri menjadi tidak berguna apabila tidak dilengkapi dengan informasi tambahan mengenai dua faktor tersebut.

\section{Pemakaian Alat/Utilisasi Availability (UA)}

UA digunakan oleh bagian produksi untuk menentukan perbandingan antara jam kerja unit (jamkerjaactualmachine) dengan jam downtime (saat machine tidak bisa bekerja karena masalah mekanis). Apabila nilai UA lebih rendah dari yang diharapkan maka produksi yang dihasilkan pun pasti akan dibawah dari yang ditargetkan. Untuk dapat mengetahui langkah apa yang harus dilakukan untuk meningkatkan availibility maka harus dilakukan analisa lanjutan terhadap jam kerja operasi dan jam downtime yang telah terjadi. Dua benchmark lainnya yang cukup sering diadopsi dan menyediakan indikator yang lebih bermanfaat adalah:

1. Mean Time Between Failure (MTBF)

MTBF merupakan pengukuran langsung untuk reliability dan dihitung dengan menggunakan rumus:

$$
\text { MT BF (jom) }=\frac{\sum \text { Toval jom Operast }}{\text { Tctal Frekumsi Breakdown Unschedule }}
$$

Ada dua hal saja yang memiliki pengaruh paling besar terhadap nilai MTBF yaitu:

a. Condition Monitoring, keefektifan dalam mendeteksi adanya masalah. Apabila problem ataupun potensial problem tidak terdeteksi atau dilaporkan maka kerusakan yang makin parah pasti akan terjadi.

b. Backlog tindak lanjut dari informasi yang didapat saat memonitor kondisi. Apabila sistem tidak merespons hasil temuan yang didapat saat melakukan condition monitoring maka problem atau kerusakan pasti akan terjadi. Gejala dan potensi masalah hendaknya selalu dianalisa dan ditentukan skala prioritasnya sehingga kerusakan yang semakin parah dan mendadak bisa dihindari

2. Mean Time To Repair (MTTR)

MTTR mengukur seberapa lambat (atau cepat) machine kembali bekerja setelah terjadi downtime.

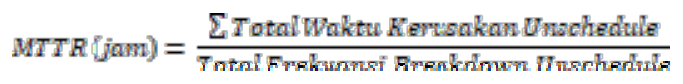

Ada beberapa hal yang mempengaruhi MTTR yaitu decision making, part availability, tools, equipment, availability bay space, dan availability man power.

\section{METODE PENELITIAN}

\section{Pengumpulan Data}

Kesiapan alat untuk produksi tergantung pada: a. Physical Availability (kesiapan unit)
Kesiapan unit penting karena jika unit tidak beroperasi maka mengurangi hasil produksi.

b. Wawancara

Wawancara adalah pengumpulan data dengan mengadakan tanya jawab secara langsung maupun tidak langsung.

c. Dokumentasi

Dalam penelitian ini dilakukan dengan cara pencatatan secara sistematis terhadap data yang diperlukan pada PT Kalimantan Prima Persada.

\section{Analisa Data}

Analisa data adalah tahapan penaksiran parameter kesiapan alat pada unit HD785-7, HD465-7 dan motor grader. Tahapan analisa data yang dilakukan meliputi:

a. Pembuatan jadwal PM

b. Analisa ekspetasi Physical Availability

\section{Teknik Penulisan}

Teknik penulisan dalam tugas akhir ini adalah akumulasi dan data kepustakaan. Data - data tersebut diproses dan dilakukan perhitungan sesuai rumus atau yang didapat dari training di perusahaan mengenai Heavy Equipment Management.

\section{Diagram Alir}

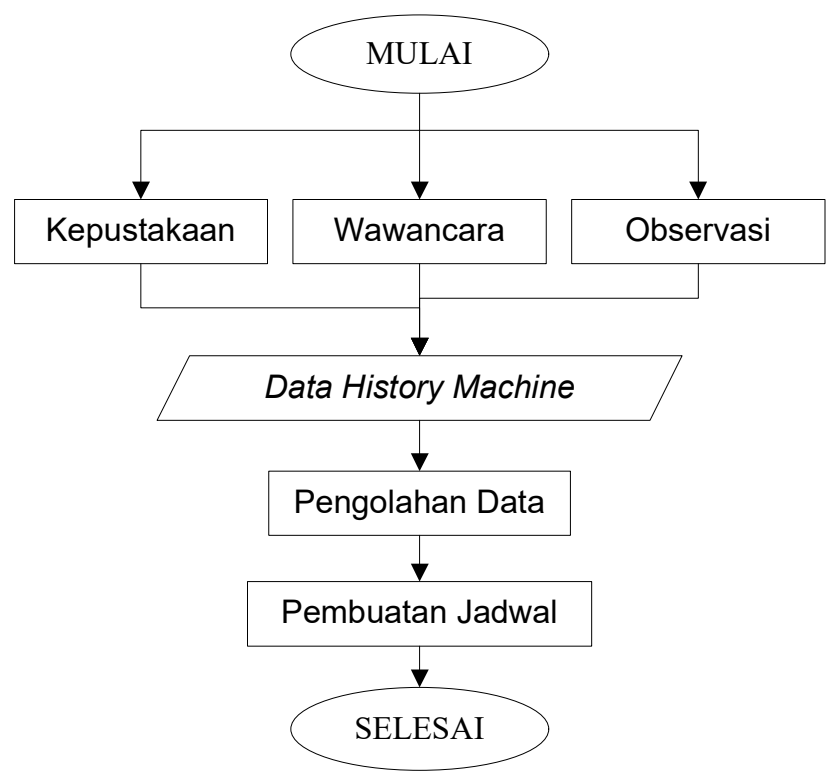

Gambar 1. Diagram Alir Penelitian

\section{HASIL DAN PEMBAHASAN}

\section{Data Umum}

Tabel 1. Data History Machine dari PT Kalimantan Prima Persada

\begin{tabular}{|c|c|c|c|l|r|}
\hline No & EGI & code_number & manufacture & date & $\begin{array}{c}\text { Hours } \\
\text { meter }\end{array}$ \\
\hline 1 & HD785-7 & DT7006 & komatsu & 1 Jan & 10175.66 \\
\hline 2 & HD785-7 & DT7007 & komatsu & 1 Jan & 9548.10 \\
\hline 3 & HD785-7 & DT7008 & komatsu & 1 Jan & 9214.29 \\
\hline
\end{tabular}




\begin{tabular}{|c|l|c|c|c|r|}
\hline 4 & HD785-7 & DT7009 & komatsu & 1 Jan & 9151.77 \\
\hline 5 & HD785-7 & DT7018 & komatsu & 1 Jan & 5813.70 \\
\hline
\end{tabular}

\section{Pembahasan dan Analisa}

Berdasarkan data History Machine dari bulan Januari 2013 yang diperolehdari PT Kalimantan Prima Persada penulis membuat schedule PM beracuan pada table estimasi dengan Service Accuracy $\pm 10 \%$. Service Accuracy (SA) adalah kemampuan untuk melakukan pekerjaan service rutin dengan interval waktu sedekat mungkin dengan waktu yang ditentukan oleh pabrik pembuat machine.

Tabel 2. Estimasi biaya dan waktu HD785-7

\begin{tabular}{|c|c|c|}
\hline Job & Cost & Duration (jam) \\
\hline PS 250 & Rp5,468,064.00 & 6 \\
\hline PS 500 & $\operatorname{Rp~7,161,548.80~}$ & 8 \\
\hline PS750 & $\operatorname{Rp~5,468,064.00~}$ & 6 \\
\hline PS1000 & Rp21,553,862.40 & 10 \\
\hline PS2000 & Rp28,271,275.20 & 12 \\
\hline
\end{tabular}

Machine : Daily operation hours $=14$ jam

Sumber PT Kalimantan Prima Persada

Tabel 3. Quantity Periodic Service

\begin{tabular}{|c|c|c|c|c|c|c|c|c|}
\hline \multirow{2}{*}{ EGI } & \multirow{2}{*}{$\begin{array}{l}\text { Code } \\
\text { num } \\
\text { ber }\end{array}$} & \multirow{2}{*}{$\begin{array}{l}\text { Periodic } \\
\text { service } \\
\text { component }\end{array}$} & jan & feb & mar & apr & mei & jun \\
\hline & & & 47 & 46 & 47 & 39 & 55 & 40 \\
\hline \multirow{5}{*}{$\begin{array}{l}\text { HD } \\
785- \\
7\end{array}$} & \multirow{5}{*}{$\begin{array}{c}\text { DT } \\
7006\end{array}$} & PS 250 & $\mathrm{~V}$ & - & $\mathrm{V}$ & - & $\mathrm{V}$ & - \\
\hline & & PS 500 & $\mathrm{~V}$ & - & - & $\mathrm{V}$ & - & $\mathrm{V}$ \\
\hline & & PS 750 & - & $\mathrm{V}$ & - & $\mathrm{V}$ & - & - \\
\hline & & PS 1000 & - & $\mathrm{V}$ & - & - & $\mathrm{V}$ & - \\
\hline & & PS 2000 & - & - & - & - & $\mathrm{V}$ & - \\
\hline \multirow[b]{2}{*}{ EGI } & \multirow{2}{*}{$\begin{array}{l}\text { Code } \\
\text { num } \\
\text { ber }\end{array}$} & \multirow{2}{*}{$\begin{array}{l}\text { Periodic } \\
\text { service } \\
\text { component }\end{array}$} & jul & ags & sep & okt & nov & des \\
\hline & & & 54 & 43 & 42 & 50 & 43 & 55 \\
\hline \multirow{5}{*}{$\begin{array}{l}\text { HD } \\
785- \\
7\end{array}$} & \multirow{5}{*}{$\begin{array}{c}\text { DT } \\
7006\end{array}$} & PS 250 & - & $\mathrm{V}$ & - & $\mathrm{V}$ & - & $\mathrm{V}$ \\
\hline & & PS 500 & - & $\mathrm{V}$ & - & - & $\mathrm{V}$ & - \\
\hline & & PS 750 & $\mathrm{~V}$ & - & $\mathrm{V}$ & - & $\mathrm{v}$ & - \\
\hline & & PS 1000 & $\mathrm{~V}$ & - & - & $\mathrm{V}$ & - & $\mathrm{V}$ \\
\hline & & PS 2000 & - & - & - & $\mathrm{V}$ & - & - \\
\hline
\end{tabular}

Setelah dilakukan perencanaan preventive maintenance didapatlah quatntity periodic service selama satu tahun. Dimana quantity service didapat tiap unitnya dan dapat diketahui quantity tiap bulannya. Dari data itu kita dapat menentukan anggaran biaya untuk pemenuhan spare part preventive maintenance selama satu tahun. Untuk menghitung biaya preventive maintenance kita perlu data harga per partnya. Berikut ini data daftar harga part

Tabel 4. Cost spare part HD785-5

\begin{tabular}{|c|c|c|}
\hline Job & Cost & Duration (jam) \\
\hline PS 250 & Rp 5,468,064.00 & 6 \\
\hline PS 500 & Rp 7,161,548.80 & 8 \\
\hline PS750 & Rp 5,468,064.00 & 6 \\
\hline PS1000 & Rp21,553,862.40 & 10 \\
\hline PS2000 & Rp28,271,275.20 & 12 \\
\hline
\end{tabular}

Sumber PT United Tractors

Dari data di atas dapat ditentukan anggaran biaya selama satu tahun untuk melakukan preventive maintenance EGI HD785-7 code number DT7006
Tabel 5. Summary yearly cost periodic service 2013

\begin{tabular}{|c|c|c|c|c|}
\hline \multirow{2}{*}{ PSC } & \multicolumn{4}{|c|}{ Bulan (dalam rupiah) } \\
\hline & jan & feb & mar & apr \\
\hline PS 250 & 5.468 .064 & - & 5.468 .064 & - \\
\hline PS 500 & $7.161 .548,8$ & - & - & $7.161 .548,8$ \\
\hline PS 750 & - & 5.468 .064 & - & 5.468 .064 \\
\hline PS1000 & - & $21.553 .862,4$ & - & \\
\hline PS2000 & & - & - & \\
\hline \multirow{2}{*}{ PSC } & \multicolumn{4}{|c|}{ Bulan (dalam rupiah) } \\
\hline & mei & jun & jul & agst \\
\hline PS 250 & 5.468 .064 & - & - & 5.468 .064 \\
\hline PS 500 & - & $7.161 .548,8$ & - & $7.161 .548,8$ \\
\hline PS 750 & - & - & 5.468 .064 & - \\
\hline PS1000 & $21.553 .862,4$ & - & $21.553 .862,4$ & - \\
\hline PS2000 & $28.271 .275,2$ & - & - & - \\
\hline \multirow[b]{2}{*}{ PSC } & \multicolumn{4}{|c|}{ Bulan (dalam rupiah) } \\
\hline & sept & okt & nov & des \\
\hline PS 250 & - & 5.468 .064 & - & 5.468 .064 \\
\hline PS 500 & - & - & $7.161 .548,8$ & - \\
\hline PS 750 & 5.468 .064 & - & 5.468 .064 & - \\
\hline PS1000 & - & $21.553 .862,4$ & - & $21.553 .862,4$ \\
\hline PS2000 & - & $28.271 .275,2$ & - & - \\
\hline
\end{tabular}

Data di atas adalah hasil anggaran perencanaan biaya selama satu tahun untuk memenuhi kegiatan operasional preventive maintenance di PT Kalimantan Prima Persada jobsite Mining Asam-Asam. Data berikut merinci pengeluaran anggaran biaya per bulan dan tiap periodik servicenya

Tabel 6. sumary monthly maintenance planning 2013 Periode 1 Jan s/d 31 Jan 2013

\begin{tabular}{|c|c|c|c|c|c|c|}
\hline \multirow{2}{*}{$\begin{array}{c}\text { Periodic } \\
\text { service } \\
\text { component }\end{array}$} & \multirow{2}{*}{ POP } & \multicolumn{5}{|c|}{ Service } \\
\cline { 3 - 7 } & $\begin{array}{c}\text { PS } \\
250\end{array}$ & $\begin{array}{c}\text { PS } \\
500\end{array}$ & $\begin{array}{c}\text { PS } \\
750\end{array}$ & $\begin{array}{c}\text { PS } \\
1000\end{array}$ & $\begin{array}{c}\text { PS } \\
2000\end{array}$ \\
\hline DT7006 & 1 & 6 Jan & 24 jan & & & \\
\hline DT 7007 & 1 & & & 15 jan & & \\
\hline DT7008 & 1 & 3 jan & 21 jan & & & \\
\hline DT7009 & 1 & 8 jan & 25 jan & & & \\
\hline DT7018 & 1 & & & & & 14 jan \\
\hline $\begin{array}{c}\text { Total } \\
\text { HD785-7 }\end{array}$ & 5 & & & & & \\
\hline
\end{tabular}

Tabel 7. summary weekly maintenance planing 2013 Periode 1 Jan s/d 5 Jan

\begin{tabular}{|c|c|c|c|c|c|}
\hline No & $\begin{array}{c}\text { Equipment } \\
\text { C/N }\end{array}$ & $\begin{array}{c}\text { HM } \\
\text { plan }\end{array}$ & activity & $\begin{array}{c}\text { lead } \\
\text { time }\end{array}$ & $\begin{array}{c}\text { due } \\
\text { date }\end{array}$ \\
\hline \multicolumn{7}{|c|}{ WHEEL } \\
\hline 1 & DT7021 & 6000 & Action PS IV & 12 & 1 jan \\
\hline 2 & DT7022 & 6250 & Action PS I & 6 & 1 jan \\
\hline 3 & DT7008 & 9250 & Action PS I & 6 & 3 jan \\
\hline 4 & DT7027 & 5250 & Action PS I & 6 & 3 jan \\
\hline 5 & GR1008 & 9750 & Action PS I & 6 & 4 jan \\
\hline 6 & GR1011 & 8000 & Action PS IV & 12 & 4 jan \\
\hline 7 & DT4056 & 23000 & Action PS III & 10 & 5 jan \\
\hline
\end{tabular}

Data di atas adalah hasil perencanaan preventive maintenance yang disusun berdasarkan monthly, dan weekly selama satu tahun periode 2013. Dapat kita lihat 
bahwa rata-rata service atau perawatan tiap unit dilakukan 2 kali dalam sebulan. Hal ini merupakan salah satu tindakan preventive maintenance guna memperpanjang life time component. Selain itu, data di atas terdapat schedule maintenance secara weekly guna mengontrol, mengawasi, dan memvalidasu kegiatan preventive maintenance unit berjalan sesuai rencana.

\section{Analisa Kejadian Tak Terduga}

Ada suatu kejadian bahwa terdapat unit DT7020 yang mengalami breakdown unshedule yang mengharuskan untuk overhaul engine, sedangkan untuk melakukan overhaul engine tersebut anggaran biaya yang telah di rencanakan selama satu tahun, unit DT7020 tidak termasuk dalam anggaran biaya overhaul engine. Alternatif solusinya dengan cara menggunakan anggaran biaya unit yang lain (DT7021) tetapi harus sesuai prosedur perusahaan yaitu change budget. Hal-hal yang perlu dipertimbangkan saat anggaran mana yang akan diambil yaitu untuk hours meter unit masih memungkinkan untuk dilakukan ekstend perbaikan/overhaul, selanjutnya dilihat dari kondisi hasil Program Pemeriksaan Machine dan hasil Program Pelumasan Analisa (kondisi sampel oli engine masih dalam performance terbaik).

\section{Analisa Hasil Physical Avaibility (PA)}

Tabel 4.8 Physical Avaibility Unit Wheel 2013

\begin{tabular}{|c|c|c|}
\hline Parameter & Actual & Target \\
\hline Jan & $91 \%$ & $90 \%$ \\
\hline Feb & $92 \%$ & $90 \%$ \\
\hline Mar & $92 \%$ & $90 \%$ \\
\hline Apr & $90 \%$ & $90 \%$ \\
\hline Mei & $93 \%$ & $90 \%$ \\
\hline Jun & $93 \%$ & $90 \%$ \\
\hline Jul & $95 \%$ & $90 \%$ \\
\hline Agust & $90 \%$ & $90 \%$ \\
\hline Sept & $92 \%$ & $90 \%$ \\
\hline Okt & $92 \%$ & $90 \%$ \\
\hline Average & $92 \%$ & $90 \%$ \\
\hline
\end{tabular}

\section{Pembahasan}

Data di atas menjelaskan mengenai kesiapan unit selama satutahun periode 2013. Dapat dilihat bahwa untuk rata-rata tiap bulan pencapaian prosentase Physical Avaibility (PA) yaitu di atas target, yang ditargetkan 90\% dan actual pencapaiannya adalah 92\%. Hal tersebut dikarenakan adanya perencanaan preventive maintenance yang telah dibuat selama setahun periode 2013 dan dikontrol adanya monthly planning dan weekly planning.

\section{Analisa Hasil Breakdown Unschedule}

Tabel 4.9 Breakdown Unschedule

\begin{tabular}{|c|c|c|}
\hline Parameter & Actual & Target \\
\hline Jan & $91 \%$ & $90 \%$ \\
\hline Feb & $92 \%$ & $90 \%$ \\
\hline Mar & $92 \%$ & $90 \%$ \\
\hline Apr & $90 \%$ & $90 \%$ \\
\hline Mei & $93 \%$ & $90 \%$ \\
\hline Jun & $93 \%$ & $90 \%$ \\
\hline
\end{tabular}

\begin{tabular}{|c|c|c|}
\hline Jul & $95 \%$ & $90 \%$ \\
\hline Agust & $90 \%$ & $90 \%$ \\
\hline Sept & $92 \%$ & $90 \%$ \\
\hline Okt & $92 \%$ & $90 \%$ \\
\hline Average & $92 \%$ & $90 \%$ \\
\hline
\end{tabular}

\section{Pembahasan}

Data di atas menjelaskan mengenai Breakdown Unschedule atau perbaikan unit yang terjadi secara tidak terenaca selama satu tahun periode 2013. Dapat dilihat bahwa untuk rata-rata tiap bulan pencapaian periode 2013. Dapat dilihat bahwa untuk rata-rata tiap bulan pencapaian prosentase Breakdown Unschedule yaitu di atas target, yang ditargetkan $50 \%$ dan actual pencapaiannya adalah 44\%. Untuk Breakdown Unschedule adalah kebalikan dari Physical Availibilty, dimana untuk PA semakin besar prosentasenya maka pencapaian tersebut dikatakan baik, semakin besar prosentasenya maka pencapaian tersebut dikatakan baik, karena berarti kesiapan unit tersebut semakin tinggi, kebalikannya untuk Breakdown Unschedule semakin kecil prosentasenya berarti hasil unit tersebut baik, karena semakin kecil Breakdown Unschedule sehingga unit sama dengan kesiapan alatnya tinggi. Hal tersebut dikarenakan adanya perencanaan preventive maintenance yang telah dibuat selama satu tahun periode 2013 dan dikomtrol adanya monthly planning dan weekly planning.

\section{KESIMPULAN DAN SARAN}

\section{Kesimpulan}

Setelah membuat Perencanaan Jadwal Preventive Maintenance $(P M)$ selama satu tahun untuk beberapa unit pada PT Kalimantan Prima Persada jobsite Mining AsamAsam, maka dapat ditarik kesimpulan sebagai berikut:

Jumlah total Preventive Maintenance setiap unit:

1. HD785-7 sebanyak 327 kali

2. HD465-7 sebanyak 162 kali

3. GD705-4 sebanyak 48 kali

4. GD825-2 sebanyak 23 kali

Dengan total biaya selama satu tahun sebesar Rp 6.765.429.092,80. Apabila perencanaan jadwal Preventive Maintenance ini dilaksanakan sesuai dengan perencanaan yang telah ditentukan maka akan diperoleh sebagai berikut:

1. Rusak mendadak menjadi minim.

2. Kesiapan alat beroperasi lebih tinggi (Physical Availability). Dengan kesiapan alat yang tinggi akan membuat produksi meningkat.

3. Ketersedian part tinggi (Part Availabity).

4. Kondisi unit selalu terpelihara.

5. Sumber daya dimanfaatkan semaksimal mungkin

6. Jangka panjangnya akan didapat nilai jual alat bekas yang tinggi.

Karena pekerjaan yang sebelumnya telah direncanakan (scheduled) untuk dikerjakan selalu akan memiliki waktu pelaksanaan yang lebih cepat dibandingkan dengan pekerjaan yang sama tetapi tidak terencana. 


\section{Saran}

1. Hendaknya sebelum melakukan pekerjaan terlebih dahulu membuat jadwal agar bisa mencapai target yang diinginkan karena pekerjaan yang sebelumnya telah direncanakan (scheduled) untuk dikerjakan selalu akan memiliki waktu pelaksanaan yang lebih cepat dibandingkan dengan pekerjaan yang sama tetapi tidak terencana (unscheduled).

2. Komitmen dalam monitoring pelaksanaan preventive maintenance sesuai schedule yang telah dibuat.

3. Pemilihan sumber daya manusia (manpower)yang memiliki skill dibidangnya.

\section{DAFTAR PUSTAKA}

[1] Gross, Jhon M. 2002. Fundamentals of Preventive Maintenance. Amacom, New York.

[2]Palmer, Richard D. 2006. Maintenance Planning and Scheduling Handbook-second edition. McGraw-Hill, New York.

[3] Raharno, Sri, dkk. 2011. Pengembangan Sistem Pengelolaan dan Penjadwalan Kegiatan Perawatan. Jurnal Teknik Mesin Indonesia, Surabaya.

[4] . 2009. Management Perawatan Alat Berat. United TractorsTraining Center, Cakung, Jakarta.

[5] 2009. Maintenance Planner. Pama-Training Center, Bogor.

[6] 2005. Shop Manual Komatsu HD785-7, HD465-7, GD7054, GD825-2.Komatsu. Tokyo.

[7]__ 2005. Operation Maintenance HD785-7, HD465-7, GD7054, GD825-2.Komatsu. Tokyo. 